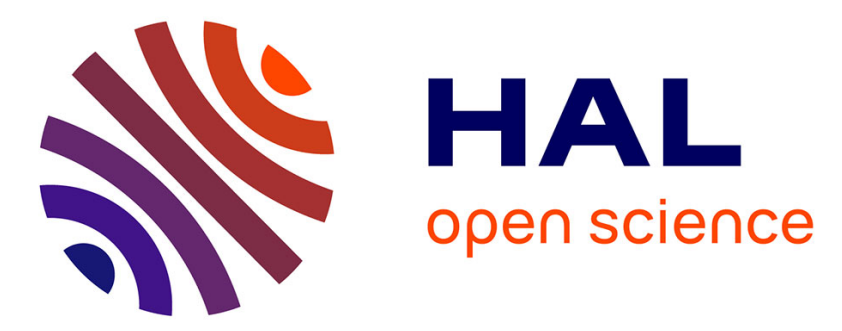

\title{
Optical study of Erbium-doped-porous silicon based planar waveguides
}

Adel Najar, H. Ajlani, Joël Charrier, Nathalie Lorrain, Severine Haesaert, Mehrezi Oueslati, Lazhar Haji

\section{To cite this version:}

Adel Najar, H. Ajlani, Joël Charrier, Nathalie Lorrain, Severine Haesaert, et al.. Optical study of Erbium-doped-porous silicon based planar waveguides. Physica B: Condensed Matter, 2007, 396 (1-2), pp.145-149. 10.1016/j.physb.2007.03.034 . hal-00275713

\section{HAL Id: hal-00275713 \\ https://hal.science/hal-00275713}

Submitted on 9 Nov 2021

HAL is a multi-disciplinary open access archive for the deposit and dissemination of scientific research documents, whether they are published or not. The documents may come from teaching and research institutions in France or abroad, or from public or private research centers.
L'archive ouverte pluridisciplinaire HAL, est destinée au dépôt et à la diffusion de documents scientifiques de niveau recherche, publiés ou non, émanant des établissements d'enseignement et de recherche français ou étrangers, des laboratoires publics ou privés.

\section{다)(1) $(5$}

Distributed under a Creative Commons Attribution - NonCommercial| 4.0 International 


\title{
Optical study of Erbium-doped-porous silicon based planar waveguides
}

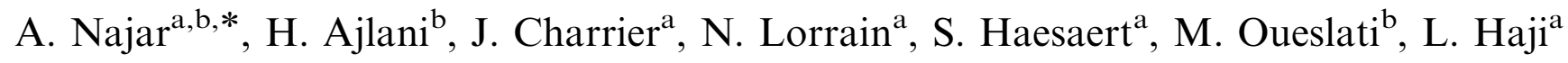 \\ ${ }^{\text {a } L a b o r a t o i r e ~ d ' O p t r o n i q u e ~ U M R ~ 6082-F O T O N, ~ U n i v e r s i t e ́ ~ d e ~ R e n n e s ~ 1, ~} 6$ rue de Kérampont, B.P. 80518, 22305 Lannion Cedex, France \\ ${ }^{\mathrm{b}}$ Laboratoire de Spectroscopie Raman, Faculté des Sciences de Tunis, 2092 ElManar, Tunis, Tunisia
}

\begin{abstract}
Planar waveguides were formed from porous silicon layers obtained on $\mathrm{P}^{+}$substrates. These waveguides were then doped by erbium using an electrochemical method. Erbium concentration in the range $2.2-2.5$ at $\%$ was determined by energy dispersive X-ray (EDX) analysis performed on SEM cross sections. The refractive index of layers was studied before and after doping and thermal treatments. The photoluminescence of $\mathrm{Er}^{3+}$ ions in the IR range and the decay curve of the $1.53 \mu \mathrm{m}$ emission peak were studied as a function of the excitation power. The value of excited Er density was equal to $0.07 \%$. Optical loss contributions were analyzed on these waveguides and the losses were equal to $1.1 \mathrm{~dB} / \mathrm{cm}$ at $1.55 \mu \mathrm{m}$ after doping.
\end{abstract}

Keywords: Erbium; Photoluminescence; Porous silicon; Waveguides

\section{Introduction}

With the increasing demand of all optical signal transmission and amplification, rare earth doped materials have had a significant impact on the area telecommunications. Erbium doped waveguide is becoming one of the key component of the planar lightwave circuits [1-3]. The great motivation is to obtain optical gain with relatively low pump power for such a component. The emission at $1.54 \mu \mathrm{m}$ from intra $4 \mathrm{f}$ shell transition of erbium is of considerable interest, since it coincides with the window of maximum transmission for silica based optical fibers. Another characteristic of the intra $4 \mathrm{f}$ transitions is their low transition probability, which makes the excited state lifetimes long enough to achieve population inversion easily [4]. This inversion is successfully utilized in erbium doped amplifiers waveguides [5,6]. Porous silicon (PS) is a promising candidate for replacing silicon as the host

\footnotetext{
*Corresponding author. Laboratoire d'Optronique UMR 6082-FOTON, Université de Rennes 1, 6 rue de Kérampont, B.P. 80518, 22305 Lannion Cedex, France. Tel.: + 332964691 15; fax: + 33296485797.

E-mail address: najar.adel@laposte.net (A. Najar).
}

material. It offers a large range of refractive indices and presents a high specific surface for element incorporations. The first work on the doping of erbium ions into PS layers was presented by Kimura et al. [7] who demonstrated stable PL at $1.53 \mu \mathrm{m}$ for samples doped using an electrochemical deposition method. Other methods were developed such as those of ion implantation [8], spin on deposited gel films [9] and immersion techniques [10].

In this paper, we present an optical study of properties of porous silicon planar waveguides (PSWG) prepared by varying the anodization current density during the formation of PS. The erbium ions were introduced into the PSWG by electrochemical deposition. The concentration profile of Er in the planar WG was determined by energy dispersive X-ray (EDX) analysis. Refractive index and porosity were determined for the WG doped erbium before and after the thermal treatment. The photoluminescence (PL) of Erbium ions in the IR range was studied with different powers of excitation. At the same time, the decay curves of the $1.53 \mu \mathrm{m}$ emission peak were characterized. Lastly, optical loss measurements at $980 \mathrm{~nm}$ and $1.55 \mu \mathrm{m}$ were investigated by measuring the light streak scattered out from the upper surface of the WG. 


\section{Sample preparation and experimental arrangements}

PS layers were elaborated by anodic etching of $\mathrm{P}^{+}$type wafer using $\left(\begin{array}{lll}1 & 0 & 0\end{array}\right)$ oriented Si substrates. The resistivity of the wafer was 4-6 $\mathrm{m} \Omega \mathrm{cm}$. The anodization was performed in an ( $\left.\mathrm{HF} 50 \%, \mathrm{C}_{2} \mathrm{H}_{5} \mathrm{OH}, \mathrm{H}_{2} \mathrm{O}: 2: 2: 1\right)$ electrolyte. A twostep anodization process was performed. At first, current density of $50 \mathrm{~mA} / \mathrm{cm}^{2}$ was applied to obtain a guiding layer (GL) with a $3 \mu \mathrm{m}$-thickness. Then, the current density was raised up to $80 \mathrm{~mA} / \mathrm{cm}^{2}$ to form the cladding layer (CL) with a $5 \mu \mathrm{m}$-thickness. Then, the Er ions were electrochemically deposited onto the PSWG at a constant current density of $0.1 \mathrm{~mA} / \mathrm{cm}^{2}$ for $10 \mathrm{~min}$. Thermal treatment of the obtained PSWG was performed using a three-step process. First, the structure of PSWG was stabilized by preoxidation at low temperature $\left(300^{\circ} \mathrm{C}\right)$ in wet $\mathrm{O}_{2}$ for $1 \mathrm{~h}$, then the PSWG was oxidized at $900^{\circ} \mathrm{C}$ in wet $\mathrm{O}_{2}$ for $1 \mathrm{~h}$. Lastly, the temperature was raised to $1000{ }^{\circ} \mathrm{C}$ in $\mathrm{N}_{2}$ gas to activate the erbium ions for $2 \mathrm{~h}$.

In order to estimate the Er concentration in the layers, SEM observations coupled with EDX analysis were performed on the sample cross section. The reflectance spectra of the porous layers (as-prepared and after thermal treatment) were obtained by a LAMBDA 900 Perkin Elmer beam spectrometer equipped with a specular reflectance module with a $6^{\circ}$ fixed angle. The parameters of thin films such as optical thickness are determined by reflectometry coupled to transfer matrix formalism. The parameters are adjusted (refractive index and thickness of layer) to fit the experimental spectra by using Bruggeman model [11]. The errors are equal to \pm 0.01 and $\pm 5 \mathrm{~nm}$, respectively, for refractive index and thickness.

The infrared photoluminescence (IR-PL) of samples was obtained from $\mathrm{Ar}^{+}$laser excitation at $488 \mathrm{~nm}$. The pump power was varied between 125 and $400 \mathrm{~mW}$ over a circular area of $\sim 1 \mathrm{~mm}$ in diameter and the laser beam was mechanically chopped. The luminescence signal was analyzed by a Jobin-Yvon monochromator and it was detected by an InGaAs photodiode. Time resolved PL measurements were performed by pumping to steady state. The pump beam was mechanically chopped and PL intensity was detected as a function of time at a fixed wavelength. The time decay signal was recorded with a digital oscilloscope. Optical losses were measured by studying the scattered light from the surface of the waveguide [12,13]. Laser light was single-mode fibercoupled into the waveguide. The intensity of the scattered light was recorded with a digital camera placed on top of the surface sample. Transverse scanning along the light propagation direction enabled the 2-D light intensity distribution of the guided modes to be obtained. The curve of light intensity as a function of z-propagation distance was obtained by integrating the data along each sampling transverse line. The light intensity decreased exponentially with the z-propagation distance. In this study, the attenuation values were the average of several measurements performed on several places of the sample.
The first 1-2 mm length from the input facet of the obtained photograph were not considered to improve the signal to noise ratio and also to avoid taking the multiple scattering at the injection point into account.

\section{Results and discussion}

In order to investigate the incorporation of Er ions into the two layers, EDX analysis was performed at different depths of the WG. The Er concentration as a function of the distance from the surface deep into the substrate for the PSWG is shown in Fig. 1. The Er concentration is nearly constant in the GL and decreases in the CL. The value of Er concentration in the GL is in the range of $2.2-2.5 \mathrm{at} \%$ (with an error of $0.1 \mathrm{at} \%$ ) which approximately corresponds to the range of $10^{19}-10^{20} \mathrm{at} / \mathrm{cm}^{3}$. So, we can consider that the doped layers are homogenous with a constant refractive index (i.e. no variation in the refractive index according to depth, for each layer).

Refractive index measurement were performed on single layer corresponding to low and high current density (50 or $80 \mathrm{~mA} / \mathrm{cm}^{2}$ ), according to as-prepared samples, after oxidation, after doping and thermal treatment. The values of refractive index are reported in Table 1. The layer from by the highest current density has the lowest index. After anodization, the index difference between the two-layers is about 0.25 . After oxidation, of course, the same trend is observed and the refractive index of each layer decreases and has a lower value than the one of silica. So, the oxidized layers remain porous. In addition, the index difference exits but decreases and is equal to 0.08. After doping, we notice that the refractive index increases due to the Er presence. For example, the refractive indices of oxidized porous layer fabricated at $50 \mathrm{~mA} / \mathrm{cm}^{2}$ for undoped and doped layer are, respectively, equal to 1.31 and 1.35. This increase of refractive index reveals the $\mathrm{Er}$ incorporation into the porous layer, that is confirmed by $\mathrm{Er}$ profile obtained by EDX. These values were also verified

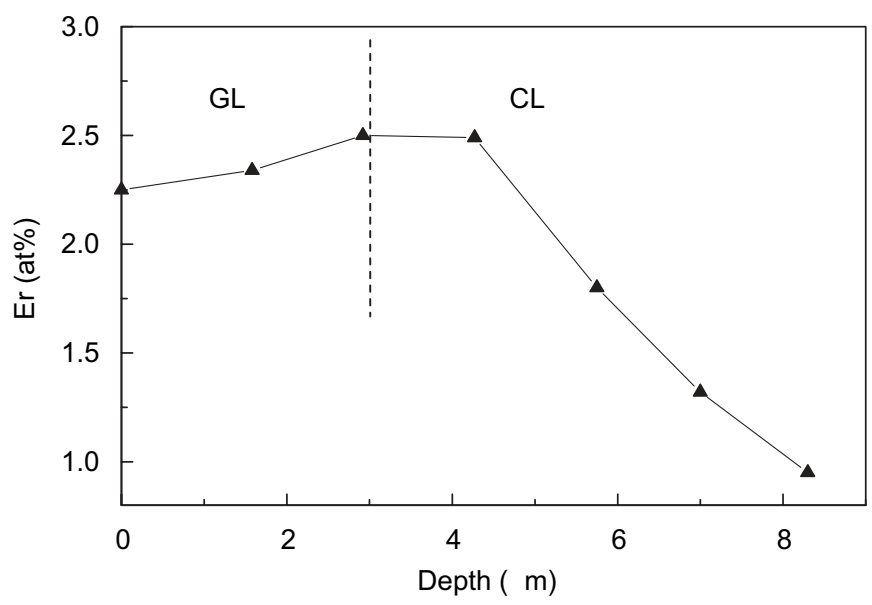

Fig. 1. Er concentration profile as a function of doped porous silicon waveguide depth (GL: guiding layer and CL: cladding layer) obtained by (EDX) analysis. 
on planar waveguides elaborated with the same conditions than those of single-layers. It is worth noting that the increase of the refractive index for the layer at $80 \mathrm{~mA} / \mathrm{cm}^{2}$ after Er doping is more pronounced, which is due to the higher porosity. This increase is normally reduced when the doping is done on wave guiding structure due to the fact that the Er is diffused trough the top GL.

Moreover, after oxidation, the thickness of layer increases due to the transformation of silicon into silica, which leads to a volumic expansion [14]. This increase was about $700 \mathrm{~nm}$ for an initial thickness of $3 \mu \mathrm{m}$ (the GL). Knowing the values of refractive index, we have evaluated the porosity of the layers by using the Bruggeman model

Table 1

Refractive index of guiding and cladding layers at $1.53 \mu \mathrm{m}$ of porous silicon planar waveguides: as-prepared, after oxidation, after doping and thermal treatment

\begin{tabular}{llll}
\hline $\begin{array}{l}\text { Current density } \\
\left(\mathrm{mA} / \mathrm{cm}^{2}\right)\end{array}$ & $\begin{array}{l}\text { Porous } \\
\text { silicon }\end{array}$ & $\begin{array}{l}\text { Oxidized porous } \\
\text { silicon }\end{array}$ & $\begin{array}{l}\text { Doped oxidized } \\
\text { porous silicon }\end{array}$ \\
\hline 50 & 1.78 & 1.31 & 1.35 \\
80 & 1.53 & 1.23 & 1.32 \\
\hline
\end{tabular}

Table 2

Porosity of guiding and cladding layers at $1.53 \mu \mathrm{m}$ of porous silicon planar waveguides: as-prepared, after doping and thermal treatment

\begin{tabular}{lll}
\hline $\begin{array}{l}\text { Current density } \\
\left(\mathrm{mA} / \mathrm{cm}^{2}\right)\end{array}$ & $\begin{array}{l}\text { Porous silicon } \\
(\%)\end{array}$ & $\begin{array}{l}\text { Doped oxidized } \\
\text { porous silicon }(\%)\end{array}$ \\
\hline 50 & $62 \pm 1$ & $28 \pm 1$ \\
80 & $71 \pm 1$ & $45 \pm 1$ \\
\hline
\end{tabular}

[15]. These values are reported in Table 2. The layer whose the refractive index is the highest is of course the lowest porosity. We notice that the porosity decreases after oxidation for each layer due to volumic expansion due to oxidation. Moreover, we assume that, for the same applied current density of anodization, the porosity of oxidized PS layer does not change in a significant manner after erbium doping.

The highly developed surface of PS is expected to enhance the diffusion and interaction of different impurities, in particular, oxygen bonding with erbium is known to be a necessary condition for the optical activity of erbium in silicon [16]. Fig. 2 shows the spectra of IR-PL intensity normalized at room temperature for doped planar waveguides after thermal treatment with different pump powers. The position of the $1.53 \mu \mathrm{m}$ peak is typical of the ${ }^{4} \mathrm{I}_{13 / 2} \rightarrow{ }^{4} \mathrm{I}_{15 / 2}$ transition between internal energy levels in $\mathrm{Er}^{3+}$ ions. The spectra have the same shape, but the PL intensity increases with excitation power. So, we can note that erbium ions were excited in two ways: direct excitation using an excitation laser and by the c-Si nanocrystallites. In the second case, porous layers were not fully oxidized. So, the oxidized porous layers contain a quantity of c-Si-crystallites, where $\mathrm{Er}^{3+}$ ions are located. Like erbium ions in nc-Si implanted in $\mathrm{SiO}_{2}$ [17], a fraction of the energy released from the recombination of electron hole centers in oxidized PS excited the Er ions [18].

The time decay of the $1.53 \mu \mathrm{m}$ emission, measured at room temperature from erbium doped planar waveguide with different excitation pump powers is shown in Fig. 3. For low power of excitation, the decay curves were adjusted using a stretched exponential. The deduced lifetime was equal to 420 and to $118 \mu$ s, respectively, for

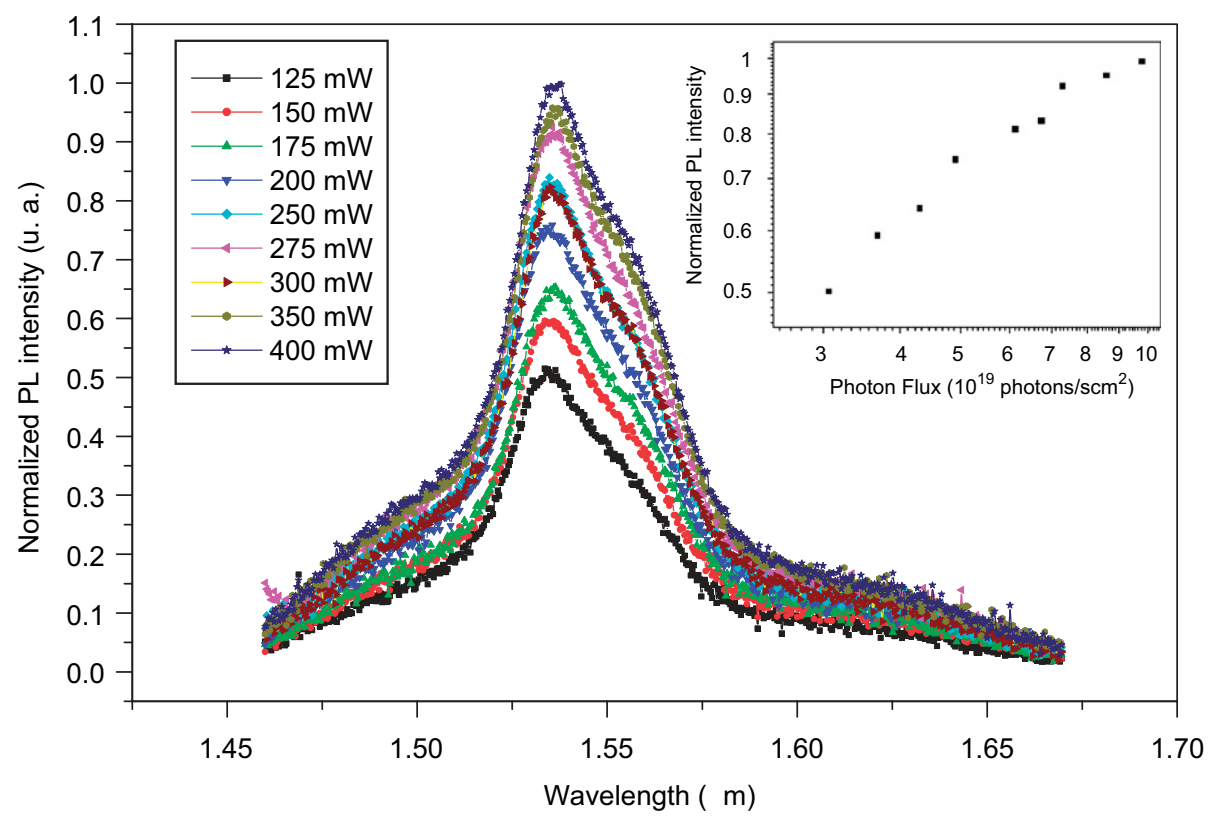

Fig. 2. Room temperature photoluminescence spectra relative to the ${ }^{4} \mathrm{I}_{13 / 2} \rightarrow{ }^{4} \mathrm{I}_{15 / 2}$ transition of $\mathrm{Er}^{3+}$ for doped porous silicon planar waveguide after thermal treatments with different excitation pump powers at $488 \mathrm{~nm}$. Inset: normalized PL intensity as a function of photon flux for a doped porous silicon planar waveguide. 


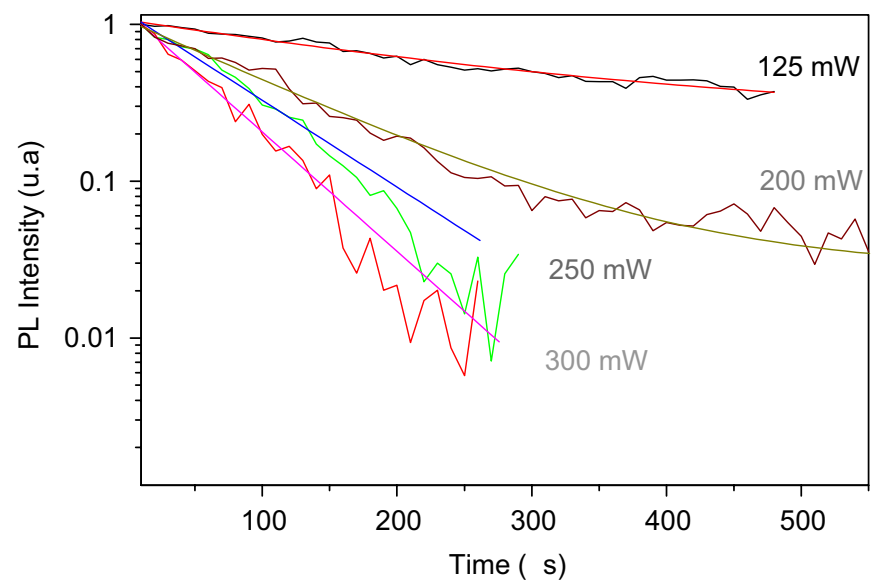

Fig. 3. Time decay of the photoluminescence intensity at $1.53 \mu \mathrm{m}$ at room temperature for a doped porous silicon planar waveguide with different excitation pump powers at $488 \mathrm{~nm}$.

125 and $200 \mathrm{~mW}$ power of excitation. This value is lower than $1 \mathrm{~ms}$ reported for Er-implanted p-type PS layers [19]. So, we believe that the microstructure of the porous material may have an effect on the PL decay time. Moreover, at high power excitation, the decay curves were adjusted by a simple exponential, and the deduced lifetime was equal to 78 and $57 \mu$ s at 250 and $300 \mathrm{~mW}$ excitation power, respectively. The variation of Er lifetime at $1.53 \mu \mathrm{m}$ as a function of pump power at $488 \mathrm{~nm}$ is shown in Fig. 4 . The radiative lifetime is related to the emission cross section. If the refractive index is assumed constant, an increase of the pump power induces a decrease of the lifetime. From the relation given in Ref. [20] and references therein, a decrease of the radiative lifetime induces an increase of the emission/absorption cross sections. This leads to an increase of the Er PL. This decrease in lifetime can be explained by an up-conversion effect due to an interaction between two Er ions both excited to the first excited state, in which one is demoted back to the ground state and one is promoted to the ${ }^{4} I_{9 / 2}$ level. Depending on whether this doubly excited state ion will decay back to the first excited state or to the ground state, this up-conversion interaction depletes the first excited state population by one or two ions. This up-conversion interaction depends on the excited $\mathrm{Er}$ concentration. Another mechanism, which could have an effect on the lifetime, is the non-radiative recombination paths such as defects in the matrix and the excited state absorption, when an excited Er ion absorbs a pump photon bringing it in the higher excited state.

The PL intensity increases with the photon flux (pump power) as shown in the inset of Fig. 2. The PL intensity increased linearly for low pump power and saturated intensity was observed at higher power. The calculated density of excited erbium in the PSWG for the maximum pump power is given by $[20,21]$ :

$N_{2}=N_{\mathrm{Er}} \sigma_{488} \tau_{\mathrm{PL}} \Phi$

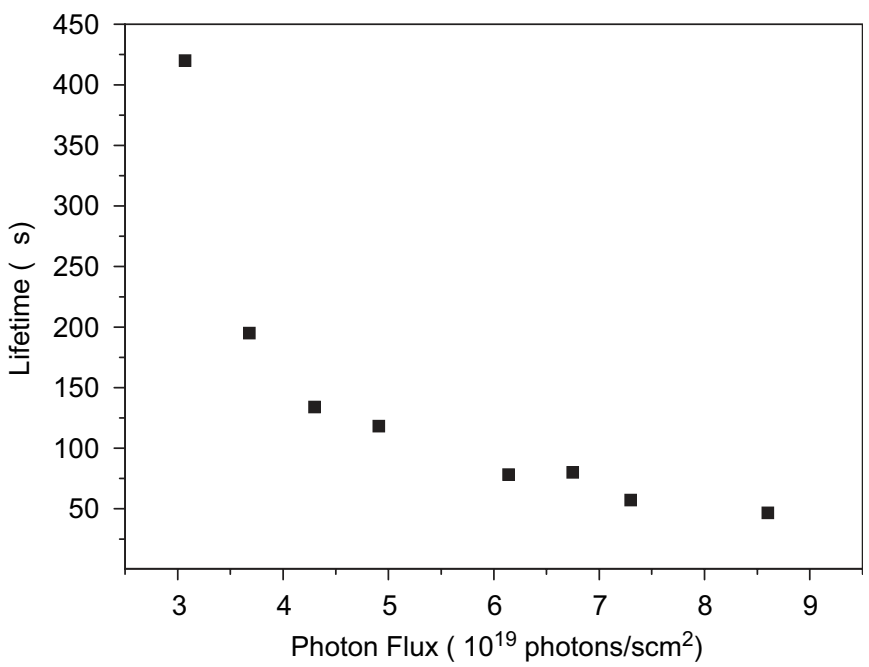

Fig. 4. Variation of Er lifetime at $1.53 \mu \mathrm{m}$ as a function of pump power at $488 \mathrm{~nm}$ due to the cooperative up-conversion mechanism obtained on a doped porous silicon planar waveguide.

With the Er density $N_{\mathrm{Er}} \approx 11 \times 10^{20} \mathrm{~cm}^{-3}$, the excitation cross section for $488 \mathrm{~nm}$ wavelength is $\sigma_{488}=1.2 \times$ $10^{-19} \mathrm{~cm}^{2}[22]$ and the measured lifetime is equal to $57 \mu \mathrm{s}$ (this value is reported in this study). The density of excited erbium in the waveguide is equal to $7.3 \times 10^{17} \mathrm{~cm}^{-3}$ at a pump flux of $9.8 \times 10^{19} \mathrm{phot} / \mathrm{cm}^{2} \mathrm{~s}$. The excited state population for the highest pump flux was around to $0.07 \%$ of the total erbium concentration. This value is lower than the values of $\mathrm{Er}$ in $\mathrm{Si}$ nanocluster where the maximum fraction of excited $\mathrm{Er}$ has been found to be equal to $1.4 \times 10^{19} \mathrm{~cm}^{3}$ at a pump flux of $5 \times 10^{20} \mathrm{phot} / \mathrm{cm}^{2} \mathrm{~s}$, corresponding to $3.2 \%$ of the total Erbium concentration $[20,21]$. Therefore, the low fraction of $\mathrm{Er}^{3+}$ that is excited in the PSWG can be attributed to the fact that the Si crystallites cannot excite the $\mathrm{Er}^{3+}$. In fact, $\mathrm{Er}$ is incorporated in the silicon in two different forms, the optically active complexes $\mathrm{Si}-\mathrm{Er}-\mathrm{O}$ and non-active $\mathrm{Er}-\mathrm{Si}$ form, respectively [23].

Optical loss measurements performed on the undoped and doped PS planar waveguides measured at $980 \mathrm{~nm}$ and at $1.55 \mu \mathrm{m}$ are shown in Table 3. The optical loss values were always higher in the case of doped PSWG. For example at $1.55 \mu \mathrm{m}$, the value of the losses was equal to $0.7 \mathrm{~dB} / \mathrm{cm}$ for the undoped PSWG and increased to $1.1 \mathrm{~dB} /$ $\mathrm{cm}$ for the doped samples. The low absorption cross section of erbium at these wavelengths and the low activated erbium fraction could explain the weak difference of losses between doped and undoped waveguides. However, this loss difference between undoped and doped waveguides can be attributed to an increase of the surface scattering after doping. In the two cases, the loss mainly depends not only on the absorption of the material but also on the interface roughness between the layers (interface scattering) and nanostructure scattering inside each layer (volume scattering) [24-26]. Finally, this relatively low optical loss for doped oxidized PS waveguides is encouraging result to achieve a net gain at $1.53 \mu \mathrm{m}$. 
Table 3

Optical losses for undoped and doped oxidized porous silicon planar waveguides at $980 \mathrm{~nm}$ and $1.55 \mu \mathrm{m}$

\begin{tabular}{lcc}
\hline & OPSW & Doped OPSW \\
\hline Losses at $980 \mathrm{~nm}(\mathrm{~dB} / \mathrm{cm})$ & $0.95 \pm 0.25$ & $1.2 \pm 0.6$ \\
Losses at $1.55 \mu \mathrm{m}(\mathrm{dB} / \mathrm{cm})$ & $0.7 \pm 0.3$ & $1.1 \pm 0.3$ \\
\hline
\end{tabular}

\section{Conclusions}

PSWGs were doped by $\mathrm{Er}$ ions by electrochemical methods. The waveguides were analyzed by EDX and reflectance spectra, respectively, to determine the Er ion profile and the refractive indices. These measurements have shown that Er concentration is homogenous in each layer of the WG. The optical activation of Er ions was verified by PL measurements. From these measurements, the excited state population at the highest pump flux corresponded to $0.07 \%$ of the total erbium concentration. Time decay as a function of the pump power shows the presence of up-conversion mechanism. Finally, the optical losses obtained from the doped OPSWs were about $1.1 \mathrm{~dB} / \mathrm{cm}$ at $1.55 \mu \mathrm{m}$. The losses were mainly due to surface scattering and Er absorption.

All these results obtained from planar waveguides hold out a promise of an optical amplification. A net gain could be expected in Er doped buried waveguides after a drastic improve of optical losses in such devices.

\section{Acknowledgment}

We thank Mr. R. Chtourou from the INRST for the PL measurements in the IR game.

\section{References}

[1] S. Coffa, G. Franzo, F. Priolo, Mater. Res. Soc. Bull. 23 (4) (1998) 25.

[2] W.J. Miniscalco, J. Lightwave Technol. 9 (1991) 234.

[3] E. Desurvire, Erbium Doped Fibre Amplifiers: Principles and Applications, Wiley, New York, 1994.
[4] H. Przybylinska, W. Jantsch, Yu.S. Belevitch, et al., Phys. Rev. B 54 (4) (1996) 2532.

[5] A. Polman, F.C.J.M. van Veggel, J. Opt. Soc. Am. B 21 (2004) 871.

[6] K. Hattori, T. Kitagawa, M. Oguma, Y. Ohmori, M. Horiguchi, Electron. Lett. 30 (1994) 856.

[7] T. Kimura, A. Yokoi, H. Horiguchi, R. Saito, T. Ikoma, A. Sato, Appl. Phys. Lett. 65 (1994) 983.

[8] F. Namavar, F. Lu, C.H. Perry, A. Cremins, N.M. Kalkhoran, R.A. Soref, J. Appl. Phys. 77 (1995) 4813.

[9] A. Dorofeev, E. Bachilo, V. Bondarenko, V. Borisenko, N. Gaponenko, N. Kazuchits, G. Troyanova, N. Vorosov, H. Gnaser, W. Bock, P. Becker, H. Oechsner, Thin Solid Films 276 (1996) 171.

[10] N.V. Gaponenko, A.V. Mudryi, O.V. Sergeev, M. Stepikhova, L. Palmetshofer, W. Jantsch, J.C. Pivin, B. Hamilton, A.S. Baran, A.I. Rat'ko, J. Lumin. 80 (1-4) (1998) 399.

[11] W. Teiss, Surf. Sci. Rep. 29 (1997) 91

[12] Y. Okamura, S. Yoshinaka, S. Yamamoto, Appl. Opt. 22 (1983) 3892.

[13] P. Pirasteh, J. Charrier, Y. Dumeige, S. Haesaert, P. Joubert, J. Appl. Phys. 101 (7) (2007) in press.

[14] K. Barla, R. Herino, G. Bomchil, J. Appl. Phys. 59 (1986) 439.

[15] D.E. Aspnes, Thin Solid Film 89 (1982) 249.

[16] D.L. Adler, D.C. Jacobson, D.J. Eaglesham, M.A. Marcus, J.L. Poate, P.H. Citrin, Appl. Phys. Lett. 61 (1992) 2181.

[17] A.M. Dorofeev, N.V. Gaponenko, V.P. Bondarenko, E.E. Bachilo, N.M. Kazucits, A.A. Leshok, G.N. Troyanova, N.N. Vorosov, V.E. Borisenko, H. Gnaser, W. Bock, H. Oechsner, J. Appl. Phys. 77 (1995) 2679.

[18] Y.H. Xie, E.A. Fitzegerald, Y.J. Mii, J. Appl. Phys. 70 (1991) 3223.

[19] N. Daldosso, D. Navarro-Urrios, M. Melchiorri, L. Pavesi, Appl. Phys. Lett. 88 (2006) 161901.

[20] M. Wojdak, M. KliK, M. Forcales, O.B. Gusev, T. Gregorkiewicz, Phys. Rev. B 69 (2004) 233315.

[21] N. Daldosso, D.N. Urrios, M. Melchiorri, C. Garcia, P. Pellegrino, B. Garrido, C. Sada, G. Battaglin, F. Gourbilleau, R. Rizk, L. Pavesi, IEEE J. Sel. Top. Quantum Electron. 12 (6) (2006) 1607.

[22] A. Najar, H. Elhouichet, N. Lorrain, M. Oueslati, Appl. Surf. Sci. 252 (2006) 5808

[23] W. Henley, Y. Koshka, J. Lagowski, J. Appl. Phys. 87 (11) (2000).

[24] P. Pirasteh, J. Charrier, Y. Dumeige, P. Joubert, S. Haesaert, L. Haji, Porous Semiconductors Science and Technology, Sites-Barcelona, 12-17 March 2006, p. 65.

[25] D. Navarro-Urrios, M. Melchiorri, N. Daldosso, L. Pavesi, C. Garcia, P. Pellegrino, B. Garrido, G. Pucker, F. Gourbilleau, R. Rizk, J. Lumin. 121 (2006) 249.

[26] P. Pellegrino, B. Garrido, C. Garcia, J. Arbiol, J.R. Morante, M. Melchiorri, N. Daldosso, L. Pavessi, E. Scheid, G. Sarrabayrouse, J. Appl. Phys. 97 (2005) 74312. 